\title{
The Cultural Capital Project: Radical Monetization of the Music Industry
}

\author{
Ian Dahlman \\ McGill University \\ ian.dahlman@mail.mcgill.ca \\ Andrew deWaard \\ University of California, Los Angeles \\ andrewdewaard@ucla.edu \\ Brian Fauteux \\ University of Wisconsin-Madison \\ brian.fauteux@gmail.com
}

\begin{abstract}
The fundamental flaw of previous attempts to monetize digital music has been the industry's insistence on treating music solely as a commodity. The digital revolution demands music be shared culture, and successful monetization will require music to be treated as such. This article outlines the ideas behind Cultural Capital, a collaborative research project that explores the theoretical trajectories, legal ramifications and technical components involved in creating a nonprofit patronage system uniting musicians and fans. Cultural Capital operates on three fronts: first, a social network of user-generated listening and sharing habits; second, opt-in tracking software that harvests the musical consumption of users, then facilitates equitable compensation to creators; third, a legal intervention aiming to provide a legitimate space for the digital consumption of music. Incorporating the multitude of individuals who propel the cultural industries, this essay argues for the establishment of a radical monetization of the music industry based on equity, connectivity and sharing.
\end{abstract}

Keywords: digital music industry, cultural capital, intellectual property, copyright, stewardship

The fundamental flaw with current attempts to monetize digital music is the industry's dogged insistence on treating music solely as a commodity. Though a contemporary phenomenon only made possible through technological developments, recorded and mass produced music has assumed a dominant position in popular culture, and its status as an industry is now commonly held to be under attack from piracy. To be clear, the music industry is not under threat; quite the contrary, it is growing like never before. The global music industry has increased by more than thirtyfive billion dollars between 2005 and 2010, the total overall sales transactions have more than doubled in the past decade, and artists' revenue share is increasing, particularly in the sectors of touring, merchandise, licensing and other non-traditional sales (Masnick and Ho 2012). In truth, it is the new viability of digital music exchange that has the major labels struggling to find ways to ensure the same degree of profits 
they had previously received from the sale of physical objects. Furthermore, the industry must now share its profit margins with the new, technology-based stakeholders that have entered into the economic equation, such as Apple. Facing a smaller piece of the pie and worried that the practice could spread further into other components of the entertainment market, the traditional cultural industries have responded with an outcry over piracy. Rather than re-evaluate themselves in this new paradigm, they have crafted a narrative in which 'pirates' have stolen their property. By confining the argument to one of rights and property, they have prevented the consideration of the shifting ontological nature of recorded music.

In one of those odd paradoxes of technology, it has taken the digital revolution to reassert an ancient, oral tradition: music as shared culture. Successful monetization will require that music be treated as such, and no longer as mere commodity. However, a vibrant community of artists and fans requires financial capital in order to foster and sustain creativity and output. With these ideas in mind, we have created the Cultural Capital project (http://cultcap.org) to explore the historical antecedents, theoretical trajectories, legal ramifications and technical components of re-envisioning an infrastructure for digital music exchange. Our goal is the creation of an online, nonprofit patronage system and social network that uses an adaptable algorithm to allocate equitable compensation via micro-payment. Incorporating the multitude of individuals who propel the cultural industries, including fans, photographers, artists, labels and others, this project argues for the establishment of a radical monetization of the music industry based on equity, connectivity and sharing. Integrating the ideas of Pierre Bourdieu, Lawrence Lessig and Jacques Attali with the praxis of our proposed internet application, we argue - in principle and practice - for the recognition and compensation of music consumers in the cultural industries, and the establishment of a sustainable infrastructure to fully embrace shared culture.

The project's name is derived from the social theorist Pierre Bourdieu who used the term "cultural capital" to outline deeply embedded systems of cultural distinction and symbolic exchange, the way by which class fractions teach aesthetic dispositions to their children and students through forms of knowledge, skills, and education. "Taste classifies, and it classifies the classifier", is his famous formulation (Bourdieu 1984: 6). Tastes, according to Bourdieu, "are the practical affirmation of an inevitable difference. It is no accident that, when they have to be justified, they are asserted purely negatively, by the refusal of other tastes" (1984: 56). From Bourdieu's perspective, cultural capital is a form of symbolic violence, part of the system of oppression that stratifies society. However, our project looks at cultural capital from the opposite perspective to consider the ways in which it creates alternative values and can operate outside the realm of purely economic capital.

Bourdieu points to the various forms of capital in artistic production, whether through consecrating works of art with symbolic capital, or accumulating cultural capital by strategically collecting, sharing and distributing cultural goods. Bourdieu explains that symbolic capital is a "'credit' which, under certain conditions, and always in the long run, guarantees "economic' profits" (1993: 75). Symbolic capital involves one making a name for one's self, "a known, recognised name, a capital of consecration implying a power to consecrate objects (with a trademark or signature) or persons (through publication or exhibition) and therefore to give value, and to appropriate profits from this operation" (Bourdieu 1993: 75). We argue for making these codes transparent and able to be tracked, so they can be leveraged to finance and support artistic production and the sharing of cultural products. What, for instance, is the potential of taste hierarchies - the ability for one listener to recommend, with a certain level of authority, a song to another - to organise the monetization of the digital music industry? One could imagine a system in which users generate cultural capital through participating in musical production, promotion and distribution, earning status and access which they 
parlay into further circulation. Leveraging this cultural capital, however, requires us to re-think the circulation of copyrighted materials in the digital age.

\section{Copyright Fetish and Digital Rupture}

Repress the natural and it comes back even stronger: not everyone can be a fetishist (Lejeune 1988: 91).

While many accounts of property focus on a "bundle of rights" (Honoré 1987: 166) conceptualised as a relationship between individuals - such as the supposedly sine qua non right to exclude (Merrill 1998: 730) - what is often cast to the side is the object of property. From this perspective, the object is the subject of property rights but not determinative of them. David Lametti, however, proposes a different metaphor from which we should approach property: "a relationship between or among individuals through objects of social wealth" (2003: 326). Forgetting the object in property analysis is to miss the limitations, purposes and community interests in a property relationship that are a function of and organised by the object itself. Objects of property "force the asymmetry of private property, its teleology, and its social aspects into account" (Lametti 2003: 377). To ignore the object is to be oblivious to the refraction of the property relation it produces, to not see that the object itself constitutes the relation as much as any actors or actions do.

The error of such an omission in analysis is exacerbated in copyright, where the object of property - the fixed expression - is not an object of inherent social wealth but rather is artificially given scarcity and value by statute for the purpose of rewarding creators. Lametti highlights that it is a prohibition on copying that reifies fixed expression into an object of property (2004: 285). Unique to copyright, then, is a situation where an object of property (fixed expression) is constructed through another object of property (the copy); to adapt Lametti's metaphor, the copyright property relationship is between individuals through an object of social wealth through another object of social wealth. By choosing to construct an object of property (and as Lametti stresses, the property relationship itself) via another object, inevitably that property relationship will mutate if the metaphysical properties of that constituting object change, typically complimented if not instigated by social and teleological shifts. And technology, the very force that produced a need for copyright in the first place, is ironically the very force that can produce such a shift in the constituting object of the copy. As a consequence, the accelerated pace of technological development beginning in the late twentieth century has ruptured copyright. By constituting the copyright property relation via the shifting copy, we unknowingly anchored the regime in the tide; little surprise now, with such a dramatic technological change, the regime seems entirely lost at sea.

The myriad of problems that plague copyright law in the digital age can be traced conceptually to its fetishization of the copy. In anthropological parlance, the copy is a totem, imbued with magical powers through the superstitious proclamation of copyright. In psychoanalytical terms, copyright is a method of staving off the anxiety of mechanical reproduction, the copy fetishized to establish control and restore the perceived wholeness of the original. And within a Marxian critique, copyright creates the copy as a site of commodity fetishism, wherein social relations are obscured by the perceived inherent value of the copy. However, the copyright's fetish only effectively operates anthropologically, psychologically and economically via the material copy that is, in analogue. The digital revolution undermined, or even completely obliterated, this carefully honed copy fetish at every site. Copyright's material fixation, in the digital age, is more Freudian than Marxian - that is, not an omnipresent, taken-for-granted premise, but a perversion.

From the Statute of Anne in the UK (the first copyright act to be regulated by government), the copy became the fetishized focus of all legality regarding intellectual 
property, fixing violation materially in a totem wherein it could be destroyed and the law could be enforced. Copyright simultaneously fetishizes and bans the graven image, the copy, the "Statu(t)e" of Anne $e^{1}$. It is an outsider's god captured in an object, an anxious legal cage of enforcement and destruction, premised upon, yet transcending, its physicality.

The myth of a right in the copy is one of an impossible whole, whereby every copy is seen to be inherently connected and controlled by its origin, rather than a totally dismembered piece in circulation. Pre-Gutenberg, this myth was sustained by the sheer costs and labour required to produce the copy, and so a technological limitation was mistaken for an essential quality of the connection between original and copy. The Gutenberg press forced the world to face the fact that the dissemination of text - and with it, knowledge, discourse and power - was not limited by any inherent essence in the original; in fact, it was just the opposite, outside the rule of the original and dictated entirely by external technologies of reproduction. What the Statute of Anne accomplished was to imbue the copy with qualities it did not have, thus relieving the anxiety and drama the Gutenberg Galaxy (McLuhan 1962) had produced. In that sense, the law re-established the mythic whole by legally fetishizing the copy, tethering it to its origin.

In legally proclaiming the copy (i.e. the copy of the expressed idea) to be a property right - separate from the property right in the raw materials of the copy - the Statute of Anne created a new commodity, one further degree abstracted from the material, a fetish in which real relations and sources of value could be further obscured. In copyright, there are two key fronts of commodity fetishizm in operation. The first is the traditional site of Marxian critique, the means of production. While copyright on its surface claims to give rights to creators such as authors and artists, the social realities of power and control over the means of production create a multitude of ways, typically by contract, wherein proprietary rights are alienated in order to create or disseminate works. So while the copy-commodity may appear to link its value directly to the creator, by creating a transferable property right copyright opens up a legally validated space for what is commonly referred to as industry middlemen. The potential for music industry exploitation is the result of the creation of an alienable right. The second front is what might be best described as the value in circulation, that is the innumerable moments wherein value is created for a copy beyond the creation and sale of the copy itself. While copyright legislation, as a balancing act between the need for just reward of a creator and the broad good of a dynamic and healthy public domain, is certainly aware of the value works provide in circulation abstractly, its fetishization of the copy inevitably buries any value created post-sale. Sharing, discussing, recommending, cataloguing, citing, curating - these are all acts of promotional and cultural labour, of creating value, which do not fit into the aforementioned, temporally limited copyright equation.

Each sense of copyright's paraphilia - anthropological, psychoanalytic, and economic - was fine-tuned for an analogue age. The accelerated development of digital and online communications technology in the late twentieth century undermined the efficacy of the copy fetish on every front. Anthropologically, digitisation meant, according to Sandy Pearlman (channeling Gertrude Stein), that "there is no there there" (2011). The material object of capture and destruction was rendered fluid, the fetishized copy no longer an efficient means of tracking transgression and enforcing the law. Psychoanalytically, the affective stop-gap measure of copyright that temporarily extended the myth of the origin-copy whole was revealed for the technological fallacy it truly was. As internet speeds and miniaturised storage capacity advanced at an exponentially accelerated rate, the copy fetish gave way, its adhesion unable to sustain the unnatural bond it presented as inherent. Economically, the internet has almost entirely ripped away the veil of the commodity fetish. Despite legal efforts to the contrary, the ability to directly connect with artists has rendered middlemen superfluous 
and their claim to copyright almost entirely unenforceable. The online traceability of the cultural labour of fans as promoters and cataloguers renders that labour visible where it was previously obscured. In short, the previously efficient analog fetishes of copyright have been rendered dysfunctional in the digital age. Copyright no longer commands the same power, respect or obedience amongst legal subjects when its fetish upon the copy is anachronistic and meaningless. The digital copy is fluid, rhizomatic, dematerialised, and defined by its circulation - it can no longer serve its function as the fetishized centre of an intellectual property regime. Not everyone can be a fetishist.

\section{The Great Library: Legal Impossibility, Virtual Reality}

The Library has existed $a b$ æternitate. That truth, whose immediate corollary is the future eternity of the world, no rational mind can doubt (Borges 1998: 113).

Over the last decade, the most striking failure of the music industry has been its inability to produce what technology promised and consumers wanted - a service that provides unlimited digital access to all recorded music. Arguably, copyright has strongly hampered the possibility of such a service. A private rights regime with so many layers and stakeholders, music copyright appears to deny even the possibility of unifying the manifold, requisite rights under one roof necessary for such an entity to be created legally. However, online extra-legal networks that facilitate the sharing of vast amounts of music between users have succeeded where the atomised rights of copyright have failed, collecting and maintaining the functional equivalent of all recorded music online. In its essence, the problem is simple. The music industries cannot legally provide that which file sharers have achieved extra-legally: The Great Library of Recorded Music. Make no mistake, it is an epic achievement, a world wonder of the digital age.

To be fair, it is unlikely that stakeholders such as the major labels ever had such an extraordinary public good as their desired destination. Patrick Burkhart and Tom McCourt stress that the preferred industry end point was always the "celestial jukebox", an infinite library coupled with a pay-for-play normativity, hoping to produce an equally infinite flow of capital (2006: 4). Perhaps it was in light of this goal that file sharers could be named pirates; glorified thieves profit(eer)ing off of an artist and label's hard work, self-interested leeches on creativity and capital, a digital hostis humanis generis which needed to be eradicated to the fullest extent possible by the law. Such a characterisation is obviously dishonest, glossing and obscuring the value sharing creates. For non-rival, non-exclusive property, to share is to promote, to create capital, and this truth stands in stark contrast to the pillaging spectre of the pirate espoused between lawsuits by the recording industry. But the most destructive legacy of this projected pirate was that by one word we were thrust into the position of those with something to gain from anachronistic copyright and pay-for-play normativity. The problem is not just that legal avenues cannot provide what has been achieved extralegally, it's that they obfuscate the potential these extra-legal achievements and norms have to offer.

Sandy Pearlman has proclaimed that online digital music is in a state he refers to as "asymptopia" (2011). Online music's expansion, he says, charts like an asymptote - a line that, while never quite reaching an axis, approaches closer and closer towards it ad infinitum. Pearlman also speaks of the unique character of file sharers, who are happy to upload and share music consistently and spontaneously with no immediate or potential financial reward. Consequently, asymptopia also incorporates utopia; in other words, asymptopia proclaims a utopian project which trends towards infinity. File sharers are engaged in a utopian project with its own self-valourising aims besides the commodity logic of both the recording industry and copyright law.

The sum of asymtopia is The Great Library, a sprawling, openly accessible monument to the recorded musical creativity of humankind, the ultimate public cultural good without gatekeepers. Digitisation of music, the connectivity of the internet and 
code-based innovations like BitTorrnet have made the Cultural Capital project possible, exemplified by (but not limited to) invite-only music sharing sites operating outside of copyright, such as the defunct OiNK and its replacements, what.cd and waffles.fm. These sites are carefully regulated communities where users must maintain healthy share ratios, which are maintained or increased by sharing (seeding) files so that other users can download them. Failure to do so typically results in suspension from the site, whether temporarily or permanently. Users often comment how these libraries are both unmatched and unprecedented. When OiNK was shut down, Trent Reznor of Nine Inch Nails made these comments to NY Magazine:

I'll admit I had an account there [OiNK] and frequented it quite often. At the end of the day, what made OiNK a great place was that it was like the world's greatest record store.

Pretty much anything you could ever imagine, it was there, and it was there in the format you wanted. If OiNK cost anything, I would certainly have paid, but there isn't the equivalent of that in the retail space (cited in Westhof 2007).

Online, we have reached asymptopia in calculus' terms - close enough for all practical purposes - but have done so without the law's consent.

Administrators on these sites often demonstrate a normativity that straddles or hybridises Mark Schultz's norms of librarians and norms of hackers (2007: 212). On the one hand, as hackers they seek to undermine the existing legal structure of copyright, their interventions buttressed by a belief in free access to computers, the freedom of information, and a general mistrust of authority. On the other hand, as librarians there is a genuine belief in the power of the public domain and a right to access, and they pour countless hours into maintaining the structure, integrity, and quality of file sharing trackers and archives. In his work, Schultz has labelled copyright a normative failure, but his few suggested solutions do not take the other normativities he charts as valid starting points, instead suggesting ways in which the existing structure can work to reshape norms (2007: 224). A new, omnipresent normativity is not something to be controlled, but is first an indication that our legal normativity needs reworking, and second, a signpost reading: Start Here.

The Great Library looms large in our digital imagination. It is a superior product and a public good, and it stands in stark contrast to what is possible under the atomised and fractured landscape of rights and interests that copyright provides. A common, preiTunes refrain was that the music industries needed to find a way to monetize online music. However, such industry visions always left the proprietary copyright model intact, and the implication was the elimination of all digital sharing - the tearing down of The Great Library. In other words, the dominant legal and industrial normativity refused to take the emergent and widespread file sharing normativity seriously. Thus, access to The Great Library is limited to those who have the technical knowledge required to share files extra-legally, or who have received an invite to a torrent sharing site. The Great Library has existed, and it is a reality from which we must chart a path. Not only have the people chosen it, they also created it and sustained it under the floorboards of the law, and have demonstrated an inherent loyalty to the preservation of the library and a society's right to access it. Cultural Capital's challenge is thus to make The Great Library just and sustainable as it is.

\section{Coding Hybridity: Towards an Alternate Digital Legality}

...the most valuable contribution to our economy comes from connectivity, not content (Lessig 2008: 89).

As one of the founders of the Creative Commons (creativecommons.org), Lawrence Lessig justifiably serves as a guiding legal inspiration for the Cultural Capital project. For our intervention, two of his principles are integral. First, his assertion that code is law guides our mode of intervention. In Code, Lessig explains that building infrastructure by code regulates online behaviour, and so code can be used to promote 
social aims and values, structuring our inter-relations as law does. By extension, building code is properly understood as a legal intervention, a voluntary restructuring of property to affect a fair flow of capital and potentially blaze the trail for new legal regimes. Second, his characterisation of hybrid economies in Remix: Making Art and Commerce Thrive in the Hybrid Economy (2008) suggests the model for our intervention. Cultural Capital aims to construct economic infrastructure both to give sharing economies legal and cultural validation, and to render them sustainable and just. By adding this dimension, the cultural work of sharing takes on a hybridised character, the economic reflecting and adding to the value of the shared, rather than acting as a gatekeeper to it.

First published in 1999, when a utopian view of cyberspace as beyond regulation predominated, Code's contrarian message was simple: code is law, its architecture is regulation, and freedom on the internet is a result not of immanence but structure. The internet has no essential nature, but rather, online "we are nature" (Lessig 2006: 338). And as equally as the internet seemed to resist regulation at the time, it also represented the potential for perfect control, challenging the liberty that was previously preserved only by the high costs of control (Lessig 2006: 196). What is most troubling to Lessig is that this control can be achieved indirectly through regulating code (2006: 136). For Lessig, we collectively sit at a crossroads where we need to make choices as to what values we wish the internet's code to reflect and entrench, as the space moves from its non-commercial roots through extensive commercial development (2006: 8). If we do not see that code is law, an architecture targeted by both business and government to control behaviour, then we risk our values playing no role in these foundational choices.

Strangely, Lessig's development of the concept is developed almost entirely from the top down. Lessig specifies four modalities of regulation - market, norms, architecture, law - which are experienced by a subject as constraints (2006: 123). However, as to the relation between modalities, he only develops examples as to how law affects constraint either directly or indirectly through the other three modes (2006: 130 ). What is lacking from his substantive analysis, but implicit in his construction, is that if code is law, then code can be written to effect new law. Certainly Lessig recognises that a value can be implemented from the bottom up: "the law could be rebalanced to encourage the freedom thought important, or this property could be redeployed to effect the freedom thought important" (2006: 199). But it is important to stress that a redeploying of property by code is most properly understood as a legal intervention; Lessig's Creative Commons is an obvious example. A code which enables behaviour, embraces and validates a normativity and facilitates the flow of capital is effecting legal change. It proposes alternative legalities. And by doing so, new code can potentially render its values intuitive to a legal imagination in the legislative branch.

Between commercial economies and sharing economies, in Remix, Lessig locates the internet's strength in the hybrid - "[t]he Internet is the age of the hybrid" (2008: 178). Lessig conceives of two kinds of hybrids: "either [it is] a commercial entity that aims to leverage value from a sharing economy, or it is a sharing economy that builds a commercial entity to better support its sharing ends" (2008: 177). In other words, the hybrid links a sharing economy to a commercial entity in order to produce value.

In his definition of a hybrid, Lessig points to something that most commercial attempts to monetize digital music have lacked: an inclusion of the sharing economy that has informed the normativity of online music since its emergence. In these previous attempts, capital has always acted as a cost of admission to a private good, ignoring the normative processes and ends of digital music. Cultural Capital takes The Great Library's sharing economy as a starting point, where people "contribute to a common good as a by-product of what they otherwise would want to do" (Lessig 2008: 155). The key difference, of course, is that our commercial aims are not personal profit, 
but the facilitation of the flow of capital to creators while recognising the value of sharing. The commercial is to be calibrated to pursue the values of the community.

Lessig tells us that this tack for hybridity can succeed because it fulfills the elements which have created success for other hybrid ventures which have had more traditional commercial aims. The key, as Jerry Yang states pointedly to Lessig, is "[y]ou have to design what the community has in mind" (Lessig 2008: 222). A sharing community must be given respect, responsibility, and belong to something with meaning (Lessig 2008: 222-223). Hybridity must honestly embrace the authority that the community already has. For Cultural Capital, The Great Library is precisely that space of authority. What the community desires is just compensation and sustainability through a cultural and legal recognition and valourisation. Lessig's hybrid suggests this goal must be the target for any economic link to succeed.

Modifying or abandoning the laws that restrict the sharing of music is needed in order to facilitate a hybrid economy in which listeners and artists can flourish. Lessig offers pointed suggestions for doing this, including ways to "enable the future", such as deregulating amateur creativity, simplifying copyright laws, decriminalising copies and, perhaps most importantly, decriminalising file sharing (2008: 251-273). Lessig lists a number of examples where online communities are disregarding copyright and asserting alternate legalities in online spaces of community and collaboration; music sites remain as a pertinent example. Nothing just "is" online, however, and the architecture of Cultural Capital would assert a restructured property relation. And if code is law online, then our code is a legal intervention, paving the way to the possibility of an entirely different legal regime. Cultural Capital aims to restructure the property in sharing digital culture so that it is just and sustainable. As such, Cultural Capital users are not consumers, not pirates, but cultural stewards.

\section{The Cultural Capital Platform}

I'm interested in utilities anyway, not manifestos. A utility adds functionality to a software system, and can be built upon in turn by further utilities later on down the road. Utilities are evolutionary rather than revolutionary (Lunenfeld 2005: 7-8).

The Cultural Capital project is currently developing an online platform in its effort to establish a non-profit infrastructure to facilitate a patronage system between artists and fans. It will operate as a social network and utilise an adaptable algorithm to allocate equitable compensation via micro-payment. Redefining what it means to be a creator of music, the Cultural Capital platform aims to realise the capital in both a listener's capacity for connection and desire to share music. No excess capital will be wasted on middlemen, and no power will be granted to gatekeepers. Rather, generated profits will be redistributed to artists and the fans whose cultural labour propels them.

The Cultural Capital platform operates on three fronts. First, it is a network where social data is aggregated and users interact. Profile pages for both artists and users are generated dynamically from public social media data. For artists, these pages would include playable music files, but they would not be hosted by the Cultural Capital platform (thus sidestepping the thorny issue of intellectual property rights). Rather, music files would be embedded by legal external services, countless of which now exist, each with unique characteristics. For example, Soundcloud is a popular distribution platform that allows music files to be posted in widgets on any website or blog and provides an API that allows others applications to access the files. There are also a number of streaming music services now available, such as Spotify, Rdio and Grooveshark (each operating on different tiers of ad-support and premium subscription), which provide comprehensive (though still limited) catalogs of searchable music from major and independent labels. These services are less directly embeddable, but they do provide the ability to post links and playlists. These services provide APIs which can be accessed to varying degrees of accessibility (e.g. not public, 
or only official affiliates). Embeddable video is also available from such popular sites as YouTube and Vimeo.

In addition to the automated aggregation of audio and video, other data streams will be incorporated into the profile pages of artists and users. Social media feeds such as Twitter and Google+ are easily incorporated as widgets, publishing the latest news feeds. Facebook is less forthcoming in allowing users to publish their profile information outside of its platform, but its "Like" button is still able to be utilised. Tour data for artists would be gleaned from Songkick, a service that indexes tour information and allows users to track their favourite bands and artists; it also provides an API which allows access to their data and integration with other services. Crowdfunding projects, facilitated by web services such as Kickstarter and IndieGoGo, could be profiled. Usergenerated content would also be featured: fan art would be sourced from deviantART, remixes from Legitmix, concert footage from YouTube, biographies and discographies from Wikipedia, concert photography from Flickr and others.

The curation of this aggregated data would be handled by a community of dedicated members, not unlike Wikipedia. Anyone could contribute, and the community would assure its quality. Rather than a market-based approach to selling fans a product through branded websites, artist pages on the Cultural Capital platform would reflect the true dynamism of music in the digital age: mixed, mediated, discussed, curated, and above all, shared. ${ }^{2}$

In addition to this standard form of aggregating social media for user profile pages, the second front of the Cultural Capital platform would specifically focus on indexing a fan's engagement with their favourite artists and their broader music community. Every time a user "liked" a new artist on Facebook, embedded a new song on Soundcloud, "favourited" a new video on YouTube, crafted a playlist on Spotify or shared a concert review on Twitter, it would be catalogued on their profile page and count toward their cultural credit. An explicit reflection of "cultural capital", these user pages would provide the data for the radical gesture at the heart of the Cultural Capital project: opt-in tracking software that would monitor the musical consumption and sharing of users and then suggest equitable payment through a micropayment subscription fee. Instead of being treated as mere consumers, forced to pay for a commodity and take part in an inequitable regime, users would be encouraged to participate in the stewardship of their favourite artists, with whom a more intimate connection would be forged. Payment would be entirely in the hands of the user; they might decide to contribute as little as a few dollars a month, to be distributed to their favourite artists and songs based on their listening data, or they might be encouraged to start donating (and hopefully eventually increase their donation) once they see their funds being allocated according to preference and distributed directly to the artists they support. Subscription - and the customisable micropayment that comes along with it -- is completely voluntary, as the Cultural Capital project aims to nurture a relationship through transparency, not realise profit through exploitation. Even the mere demonstration of equitable payment and a sustainable infrastructure will have an impact on skeptical users.

An effective online tracking mechanism for listening habits already exists, Last.fm, which provides a model both in its successes and its failures. Last.fm excels in building detailed profiles of its user's musical tastes by recording details of the songs each user listens to on a variety of platforms. Whether recorded through a plug-in for a music application (iTunes, Spotify, Rdio, Pandora, Winamp, and many more) or a piece of standalone software that monitors other music devices (e.g. iPod, Xbox, smart phones), the information is indexed in Last.fm's database, then displayed in list form on a user's profile page and also compiled for each artist page, thus keeping a running tally of fan engagement. The service also excels in providing an accessible and adaptable API, allowing users to interact with and publish their data in a variety of ways. In conjunction with the ability for users to cross-reference their profile with their friends and similar users, Last.fm has developed into a sophisticated recommendation 
engine. Since being bought by CBS/Viacom in 2007, however, the company has been attempting to monetize its service through advertising and a subscription model for its radio service. This wealth of significant cultural data and interaction is being wasted on a system that continues to treat music as a commodity.

The Cultural Capital platform, on the other hand, would utilise such data in order to provide the user with a fully customisable and flexible payment method with which to support their favourite artists. Subscribers would choose how much money they wish to contribute each month (suggested prices would be matched with their income bracket), then they would control a dashboard of sliding scales to visualise their payment distribution. For instance, a user may wish to base their payment on the artists or songs they individually choose to support (their "Likes" and "Favourites"), or they might prefer to let an algorithm allocate funds based on specific properties, such as "most listened", "most in need of funding for their next recording", "most local" and, "most shared in my social network". A combination of any of these properties would also be possible and codes of conduct for cultural stewardship would be encouraged, promoting ethical consumption by users and ethical production/distribution by artists.

There would be much value-added potential for users participating in this system: cultural sustainability (most people want to support artists, just not the exploitative practices of an unfair oligopoly), status and distinction (a largely untapped motivating factor in the consumption of music), social connection (cultural consumption being a key medium for contemporary interpersonal relationships), and a subsequent addition to the system would be establishing a credit system that rewards users for their cultural labour. For example, access to exclusive material supplied by participating artists and record labels can be offered to users who have been particularly active in sharing an artist's music. But it is artists and creators who have the most to gain from the Cultural Capital interface. They will be compensated by receiving capital directly from users, circumventing industry intermediaries of the outdated big music industry model. Initially, the Cultural Capital system would actually realise surplus profit for the current record industry, but it would slowly shift the rules of the game; users and artists would become both distribution and promotion, legitimising the unacknowledged roles which they already play.

One of the reasons why such a system has not yet been created is that the technology for diffused distribution and micro-payment is still in its infancy. Micropayment refers to an online, financial transaction of a small sum of money, though just how small that sum can be has been limited by the transaction costs of credit card companies and e-commerce businesses such as PayPal. Recent innovations have begun to bring that cost down, such as micro-payments being configured to be charged to mobile phone bills, as well as 'micro-donation' systems such as Flattr, a platform similar to what the Cultural Capital project envisions. With Flattr, a user pays a monthly fee of their own choosing, a portion of which is paid out to each website they "flattr", a system comparable to an internet tip jar.

The disadvantages of Flattr are twofold. First of all, content creators must opt in to the system by adding a flattr button to their website; as such, it is unlikely to be broadly implemented because it is so antithetical to the current economic logic of the cultural industries. Major corporations are not likely to allow the price of their product to be controlled by the consumer. The Cultural Capital platform would avoid this obstacle by simply imposing its vision on top of the music industry, linking artists and fans together in a voluntary donation relationship, rather than allowing its reach to be limited by outdated legal regimes. Furthermore, Flattr is still operating under the logic of the creator/consumer divide. Rather than a mode of production and consumption, the Cultural Capital platform advocates a model based on creation and circulation, where fans are imbricated in cultural creation. In essence, we would be expanding Flattr from a niche, one-way product into an extensive, two way system. 
The third front of the Cultural Capital project is its legal platform, aiming to provide a legitimate and just space for the digital consumption and promotion of music. New models for managing intellectual property rights will be explored and integrated, emphasising that users participate in all facets of the industry: we are now all producers, consumers, promoters, distributors, curators and librarians. As such, we should be treated as stewards of cultural goods rather than trespassers of a property that, in practice, is never private.

The Cultural Capital project is a legal intervention. It seeks to demonstrate that copyright's goal - the just reward of creators - can be accomplished without a private property regime. Cultural Capital's code is a law best described as stewardship, enabling responsible consumption, sustainability by financing creators, and the best interests of the collective in regard to a public good. It rejects the criminalisation of digital music sharing normativity and instead seeks to validate the value and capital created by sharing, its guiding normativity. It is a librarian's law for The Great Library, rendering it a legal hybrid economy.

Importantly, in no way does the Cultural Capital platform violate copyright law. Circulation, or the 'making available' of digital files and copies, is a phenomenon that occurs outside Cultural Capital's confines that is independent of its encouragement. Rather, Cultural Capital enables users to assert a different legal imagination, where creators are still compensated but copyright gatekeepers are forsaken, and sharing is included in the commercial equation. It is the first, voluntary step towards an alternative digital music legality.

\section{Conclusion}

Our music foretells our future. Let us lend it an ear (Attali 1985: 11).

In Noise: The Political Economy of Music, Jacques Attali reminds us that music is not only intimately tied to the mode of production in any given society, it actually presages social revolutions. From music's role as ritual in primitive societies, to the commodification of the musician before the French Revolution, to the role of the phonograph and the radio in facilitating a society of repetition, music is a system of prophecy. Attali (1985) outlines three cultural stages in history and presages a fourth, each linked to a mode of production and cultural logic of music: Sacrificing, Representing and Repeating; and then the augured stage of Composing. Our contemporary copyright laws and economic paradigms still operate and perpetuate the constraints of the repetition stage, in which music is mechanically reproduced, commodified, and stockpiled, but we would be wise to consider the ways digital music might be suggesting an alternative mode of production.

In his final chapter on Composition, Attali claims that there is the potential for "the advent of a radically new form of the insertion of music into communication", overturning all concepts of political economy (1985: 134). Composition would involve the making of music for one's own pleasure, and not for the accumulation of value, and he emphasises that composition also calls into question the distinction between "worker and consumer". As Attali writes, "Music is no longer made to be represented or stockpiled, but for participation in collective play" (1985: 141). He begins outlining the technologies for which to facilitate this era, noting that devices like the tape recorder and photography will mutate the consumer to a producer. Nowadays, there are countless ways that listeners and music fans "produce" music and culture, and we need a model that recognises and allows for this renewed participation. "If representation is tied to printing", says Attali, "and repetition to recording...composition is tied to the instrument" (1985: 51). Unbeknownst to Attali, this instrument would be the internet, the ultimate musical instrument for collective production and play. The Round Dance - the culmination of twenty-five centuries of musical struggle Attali anticipates, signalling a post-capitalistic future - occurs in the electronic global village. 
The technology exists to enable musicians and artists to sustain themselves through the involvement of listeners as funding patrons and as cultural intermediaries that are central to the circulation of music and culture. There is no accumulation of profit; instead, cultural capital is distributed directly.

The Cultural Capital platform encourages and monetizes creativity through a cultural philosophy that exploits unique advantages of the contemporary musical, social, and technological environment. It aims to facilitate the payment of both artists and fans for their creative efforts, while also crafting legal and theoretical arguments for a more open copyright regime. We are working toward establishing the infrastructure to fully embrace shared culture, guided by cultural theorists and legal scholars who have anticipated this intervention through their writing. This radical monetization is an intentional misnomer: radical in its scope of overhauling the infrastructure of the music industry perhaps, but almost banal in its effort to simply give both musicians and listeners what they want.

\section{Endnotes}

\footnotetext{
${ }^{1}$ We are indebted to Sandy Pearlman for the pun.

${ }^{2}$ See the Resources section of cultcap.org for an up-to-date, annotated listing of the vast array of innovative internet resources available to musicians and fans, such as SoundCloud, Songkick, Last.fm, or Kickstarter.
}

\section{Acknowledgements}

The Cultural Capital project is sponsored by an Art+Exchange planning grant from the University of California Institute for Research in the Arts.

\section{References}

Attali, Jacques (1985) Noise: The Political Economy of Music. Brian Massumi trans. Minneapolis: Minnesota University Press.

Borges, Jorge Luis (1998) Collected Fictions. Andrew Hurley trans. New York: Penguin Books.

Bourdieu, Pierre-

(1984) Distinction: A Social Critique of the Judgement of Taste, trans. Richard Nice. Cambridge: Harvard University Press.

(1993:1986) The Field of Cultural Production: Essays on Art and Literature. Randal Johnson Ed. New York: Columbia University Press.

Burkart, Patrick and McCourt, Tom (2006) Digital Music Wars: Ownership and Control of the Celestial Jukebox. Oxford: Rowman \& Littlefield.

De Block, Andreas (2004) Genital Constructions: A Critique of Freud's 'Fetishism.' In C. Gemerchak Ed. Everyday Extraordinary: Encountering Fetishism with Marx, Freud, and Lacan. Leuven: Leuven University Press: 83-96.

Honoré, Tony (1987) Making Law Bind: Essays Legal and Philosophical. New York: Oxford University Press.

Lametti, David(2003) The Concept of Property: Relations through Objects of Social Wealth. University of Toronto Law Journal 53: 325-378.

(2004) The Concept and Conceptions of Intellectual Property as seen through the Lens of Property. In G Comandé and G Ponzanelli Eds. Science and the Law in the Prism of Comparative Law. Torino: Giappichelli: 269-295. 
Lejeune, Philippe (1988) Maupassant et le fétichisme. In J. Lecarne and B. Vercier Eds. Colloque de Cerisy, Maupassant, mirroir de la nouvelle. Paris: Presses universitaires de Vincennes, Saint-Denis: 91-109.

Lessig, Lawrence-

(2006) Code Version 2.0. New York: Basic Books.

(2008) Remix: Making Art and Commerce Thrive in the Hybrid Economy. New York: Penguin Press.

Lunenfeld, Peter (2005) User: InfoTechnoDemo: Mediaworkbook. Cambridge: MIT Press.

Marx, Karl (1967) Capital. Samuel Moore and Edward Aveling trans. New York: International Publishers.

Masnick, Michael and Ho, Michael (2012) The Sky is Rising: A Detailed Look at the State of the Entertainment Industry. http://www.techdirt.com/skyisrising Accessed: 6 Feb. 12.

McLuhan, Marshall (1962) The Gutenberg Galaxy: The Making of Typographic Man, Toronto: University of Toronto Press.

Merrill, Thomas (1998) Property and the Right to Exclude. Nebraska Legal Review 77: 730-755.

Nielson (2012) The Nielson Company \& Billboard's 2011 Music Industry Report. http://narm.com/PDF/NielsenMusic2011YEUpdate.pdf Accessed: 5 Mar 2012.

Pearlman, Sandy (2011) Analog Copyright. McGill Faculty of Law, McGill University. Montreal, September 2011.

Schultz, Mark F. (2007) Copynorms: Copyright Law and Social Norms. In Peter K. Yu Ed. Intellectual Property and Information, Volume 1: Copyright and Related Rights. Westport: Praeger Publishers: 201-236.

Statute of Anne 1710. (8 Anne, c. 19). London: HMSO.

Westhof, Ben (2007) Trent Reznor and Saul Williams Discuss Their Collaboration, Mourn OiNK. NY Magazine - Vulture Blog, 30 October, http://nymag.com/daily/entertainment/2007/10/trent reznor and saul williams.html Accessed: 10 Feb 2012. 